\title{
Clinical Validation of ELISA Assays for Insulin-Like Growth Factor-II (IGF-II)
}

\author{
Sadie J Redding, Gwen Wark ${ }^{\mathrm{a}}$, Callum Livingstone ${ }^{\mathrm{a}, \mathrm{b}, \mathrm{c}}$
}

\begin{abstract}
Background: Insulin-like growth factor-II (IGF-II) is known to be dysregulated in malnutrition and in non-islet cell tumour hypoglycaemia (NICTH). Its measurement may be used diagnostically in the latter condition but little information is available on its utility as a nutritional marker. The aims of this study were to clinically validate two ELISAs for measurement of IGF-II in these conditions and to provide further information relevant to their use in nutritional contexts.
\end{abstract}

Methods: IGF-II concentrations were measured by extraction and non-extraction ELISA and RIA in 20 malnourished patients referred for nutrition support. IGF-II concentrations were also measured by both ELISAs in 10 subjects with clinical features of NICTH.

Results: Baseline IGF-II measured by both ELISAs correlated with body weight in patients referred for parenteral nutrition (PN) (P $<0.05)$. Following commencement of PN, IGF-II concentrations climbed from baseline reaching statistical significance at days 5 and 7 of $\mathrm{PN}(\mathrm{P}<0.05)$. In specimens from subjects considered to have NICTH, IGF-II results from both ELISAs were positively biased compared to those measured by RIA. In comparison to RIA, the non-extraction ELISA yielded two false positive results and the extraction ELISA one false positive and one false negative result.

Conclusions: IGF-II may have a place in monitoring of nutrition support and merits further study of its utility as a nutritional marker.

\footnotetext{
Manuscript accepted for publication April 12, 2012

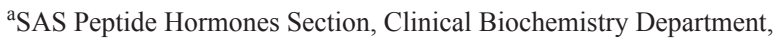
Royal Surrey County Hospital. Guildford, Surrey, GU2 7XX, UK

${ }^{b}$ Faculty of Health and Medical Sciences, University of Surrey,

Guildford, Surrey, GU2 7XH, UK

${ }^{\mathrm{c}}$ Corresponding author: Callum Livingstone.

Email: callum.livingstone@nhs.net

doi: $10.4021 /$ jem 82 w
}

Whilst the ELISAs investigated can sensitively detect IGF-II and are valid for the measurement of IGF-II in nutritional contexts they are unlikely to replace RIA for the purpose of investigating NICTH.

Keywords: IGF; Malnutrition; Hypoglycaemia; Immunoassay

\section{Introduction}

The insulin-like growth factor (IGF) system consists of the peptide hormones IGF-I and IGF-II, cell surface receptors and circulating IGF binding proteins (IGFBPs) [1]. IGF-I and $-\mathrm{II}$ are the primary growth-promoting members of the system, mediating the effects of growth hormone $(\mathrm{GH})$. Both are small, single chain polypeptides having approximately $70 \%$ sequence identity. They bind to the type 1 IGF receptor and insulin receptor activating the receptor tyrosine kinase activity. The activated receptors initiate signalling cascades, resulting in the regulation of a number of biological responses.

The IGF-II gene encodes a 180 -amino acid protein, known as pre-pro-IGF-II. This consists of a 24 -amino acid signal peptide at the $\mathrm{N}$-terminus, the 67 -amino acid mature IGF-II peptide $(7.5 \mathrm{kDa})$ and an 89 -amino acid extension, the E-domain, at the C-terminus [2]. This precursor is proteolytically processed to pro-IGF-II and finally IGF-II itself. The physiological role of IGF-II is less well understood than that of IGF-I, but it is thought to be involved in cell growth, cell division, foetal differentiation and metabolic regulation. Its expression is influenced by hormones viz oestrogen, adrenocorticotrophic hormone, luteinizing hormone, follicle stimulating hormone and human chorionic gonadotrophin, as well as by other growth factors, such as platelet-derived growth factor, epidermal growth factor, and fibroblast growth factor [3].

There is considerable evidence for dysregulation of IGFs in disease states. Numerous studies have observed serum IGF-I concentrations to be reduced in malnourishment and to respond to nutrition support [4-6]. As such, IGF-I has clinical utility as a marker of nutritional status but the presence of conditions such as liver and renal disease, acute 
Table 1. Baseline Characteristics of Study Subjects

\begin{tabular}{lccc}
\hline Parameter & Mean & SD & Range \\
\hline Age & 58.8 & 12.5 & $37-77$ \\
Weight $(\mathrm{kg})$ & 68.2 & 14.9 & $37-102$ \\
Weight loss (\% in 6 months) & 6.6 & 6.8 & $0-21$ \\
BMI $\left(\mathrm{kg} / \mathrm{m}^{2}\right)$ & 24.1 & 4.3 & $14.5-34.1$ \\
'MUST' score & 2.9 & 0.7 & $2-4$ \\
\hline
\end{tabular}

phase responses (APRs) and hypopituitarism can confound its interpretation. To date relatively few studies have investigated IGF-II in nutritional contexts but in common with other IGF axis proteins, it appears to be dysregulated in under and over nutrition. Counts et al [5] observed that serum IGF-II was $27 \%$ lower in underweight patients compared to normal control subjects and increased upon refeeding. Conversely, obesity is associated with elevated concentrations of free and total IGF-II compared to lean controls [7, 8]. These findings suggest that IGF-II is worthy of investigation as a potential marker of nutritional status. Factors confounding its interpretation as a nutritional marker have not been well studied.

IGF-II is also dysregulated in non-islet cell tumour hypoglycaemia (NICTH) [9]. This is a rare paraneoplastic syndrome in which tumours, commonly advanced retroperitoneal tumours, may secrete excessive IGF-II and 'big IGFII'. These peptides mimic the action of insulin promoting peripheral glucose uptake and suppressing hepatic glucose output causing severe hypoglycaemia [10]. Currently, investigation of possible NICTH is the only established clinical indication for measurement of IGF-II, the most useful parameter being the IGF-II: IGF-I molar ratio. Teale and Marks originally suggested that the IGF-II: IGF-I molar ratio might prove useful in the diagnosis of NICTH in cases where the IGF-II concentration alone is normal or slightly elevated [9]. This has been confirmed by subsequent studies, a molar ratio of $>10$ considered consistent with a diagnosis of NICTH [11].

In the Peptide Hormones Supra-Regional Assay Service (SAS) laboratory in Guildford IGF-II is currently measured by in-house radioimmunoassay (RIA) (IGF-II-IGF-I molar ratio reference range $<10$ ). This RIA has previously been validated against size exclusion chromatography [12]. There would be potential advantages to measuring IGF-II by enzyme-linked immunosorbent assay (ELISA) namely reduced costs, avoidance of radioactivity and the possibility of results within one day. The latter would be desirable if results were to be used in managing nutrition support. In addition, an ELISA could potentially be included in the repertoire of non-specialist laboratories. In order to measure 'big IGF-II', size exclusion chromatography can be used to separate, the 'big' and mature forms of IGF-II which are then assayed by RIA, using an antibody with cross-reactivity to both [12] Semi-quantitative western blotting methods have also been used to measure both forms of serum IGF-II [13].

In order to clinically validate IGF-II measurement by ELISA it was chosen to measure IGF-II in malnourished patients referred for nutrition support. The serum IGF-II concentrations in these patients would be expected to correlate with anthropometric measurements and to climb in response to nutrition support. Another aim of this part of the study was to provide information relevant to the utility of IGF-II as a nutritional marker in this group of patients. As the second part of the clinical validation, it was investigated whether the ELISAs could detect elevated concentrations of IGF-II and 'big-IGF-II' in patients with clinical features consistent with NICTH.

\section{Methods}

\section{Patient recruitment and sample collection}

Patients referred to the nutrition support team (NST) at the Royal Surrey County Hospital (RSCH) for parenteral nutrition (PN) were recruited for the study between August and November 2008. All received PN for at least six days and had specimens taken at baseline and days three, five and seven. Weight, percentage weight loss over six months, BMI and malnutrition universal screening tool ('MUST') [14] score were recorded. The 'MUST' score takes account of BMI, recent weight loss and acute disease. A score $\geq 2$ suggests high nutritional risk and indicates referral for consideration for nutritional support. Ten serum samples were also collected from patients with features suggestive of non-islet cell tumour hypoglycaemia (NICTH) whose IGF-II: IGF-I molar ratio had previously been measured by the SAS. Healthy 
Table 2. Correlates of Baseline IGF-II Concentrations (Measured By ELISA) and IGF-II: IGF-I Ratio in Patients Referred for Parenteral Nutrition

\begin{tabular}{|c|c|c|c|c|}
\hline & \multicolumn{2}{|c|}{$\begin{array}{l}\text { IGF-II } \\
\text { (extraction ELISA) }\end{array}$} & \multicolumn{2}{|c|}{ IGF-II:IGF-I molar ratio } \\
\hline & $\mathbf{r}$ & P value & $\mathbf{r}$ & P value \\
\hline BMI $\left(\mathrm{kg} / \mathrm{m}^{2}\right)$ & 0.4523 & 0.0615 & 0.4606 & $0.0410^{*}$ \\
\hline$\%$ weight loss (last 6 months) & 0.2321 & 0.3248 & 0.2686 & 0.2521 \\
\hline 'MUST' score & 0.2820 & 0.2283 & 0.0392 & 0.8697 \\
\hline \multirow[t]{3}{*}{ Weight (kg) } & 0.5206 & $0.0186^{*}$ & 0.3950 & 0.0848 \\
\hline & \multicolumn{2}{|c|}{$\begin{array}{l}\text { IGF-II } \\
\text { (non-extraction ELISA) }\end{array}$} & \multicolumn{2}{|c|}{ IGF-II:IGF-I molar ratic } \\
\hline & $\mathbf{r}$ & P value & $\mathbf{r}$ & P value \\
\hline BMI $\left(\mathrm{kg} / \mathrm{m}^{2}\right)$ & 0.5131 & $0.0207 *$ & 0.2814 & 0.2295 \\
\hline$\%$ weight loss (last 6 months) & 0.1997 & 0.3985 & 0.2466 & 0.2947 \\
\hline 'MUST' score & 0.1541 & 0.5166 & -0.1521 & 0.5220 \\
\hline Weight $(\mathrm{kg})$ & 0.5370 & $0.0146^{*}$ & 0.0848 & 0.7221 \\
\hline
\end{tabular}

Pearson correlation analysis ( $r$ ) was used for the IGF-II data and the IGF-II: IGF-I molar ratio. A two-tailed p-value was used to assess the significance of the correlation identified. ${ }^{*} \mathrm{P}<0.05$.

volunteers to provide specimens used for the method comparison were recruited from laboratory personnel. This work was approved by the South West Surrey Local Research Ethics Committee (REC reference no. 07/Q1909/86).

\section{General chemistry}

Serum biochemical markers of liver, renal and bone dysfunction and CRP were assayed on the Advia 2400 and 1650 Chemistry Systems (Siemens Healthcare Diagnostics, Surrey, UK). Following analysis, serum specimens were frozen at $-20{ }^{\circ} \mathrm{C}$ prior to IGF assay.

\section{IGF-II enzyme-linked immunosorbent assay (ELISA)}

Two commercially available ELISA's were evaluated viz an extraction assay (Active IGF-II ELISA DSL-10-9100) and a non-extraction assay (Active IGF-II ELISA DSL-10-2600) (Diagnostic Systems Laboratories, Inc. (DSL) now owned by Beckman Coulter UK Ltd, High Wycombe, UK). The extraction ELISA involved extracting IGF-II from binding proteins, effectively measuring total IGF-II. Both IGF-II ELISAs were enzymatically amplified two-step sandwich-type immunoassays. Standards, controls and patient samples were incubated in microtitration wells, coated with anti-IGF-II antibody. Following incubation and washing, the wells were treated with an anti-IGF-II antibody labelled with horseradish peroxidase (HRP) and after a second incubation and washing step, the wells were incubated with tetramethylbenzidine (TMB). Enzymatic turnover of TMB was determined by dual wavelength absorbance measurement at 450 and 620 $\mathrm{nm}$, the absorbance measured being directly proportional to the IGF-II concentration present.

\section{IGF-II radioimmunoassay (RIA)}

IGF-II was also measured by in-house RIA which used a mouse monoclonal anti-IGF-II antibody (Millipore, Watford, 

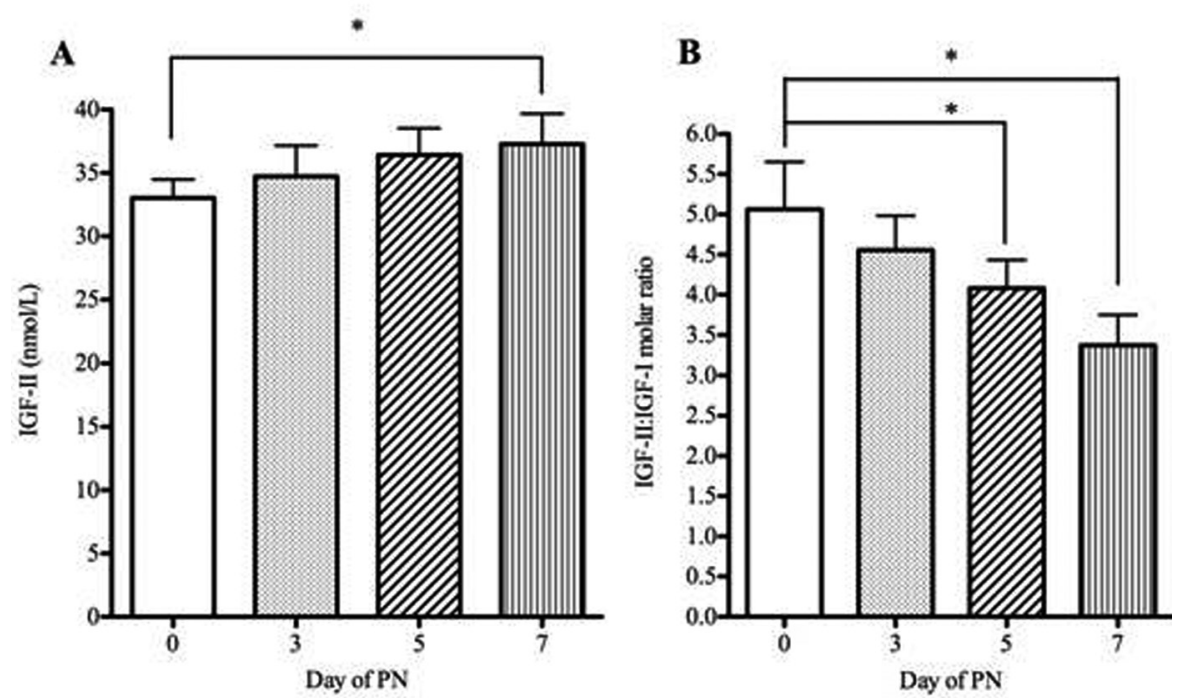

Figure 1. IGF-II concentrations measured by RIA and IGFII-IGF-I molar ratio in patients receiving parenteral nutrition. Serum IGF-II (A), IGF-II:IGF-I molar ratio (B) in patients at baseline (day 0) and days three, five and seven of PN administration. Serum IGF-II and the IGF-II: IGF-I molar ratio were tested for significance using repeated measures ANOVA with Dunnett's multiple comparison tests. ${ }^{*} \mathrm{P}<0.05$. Error bars are $+\mathrm{SEM}$.

UK) and recombinant IGF-II standard (Bachem UK Ltd, St. Helens, UK). ( ${ }^{125}$ I)-IGF-II label was prepared by in-house iodination. Serum samples, standard and controls containing protein-bound IGF-II were extracted with acid-ethanol to precipitate binding proteins prior to analysis. Radioactivity was counted using an LKB 1260 multigamma counter.

\section{IGF-I immunoassay}

IGF-I was measured using a solid-phase, enzyme-labelled chemiluminescent immunometric assay, performed on an Immulite analyser with reagent kits obtained from Siemens Healthcare Diagnostics and following the manufacturer's instructions. The method uses a mouse monoclonal anti-IGF-I capture antibody and a rabbit polyclonal antibody conjugated with alkaline phosphatase as the secondary antibody.

\section{Statistical analysis}

All statistical analysis was carried out using GraphPad Prism 5.0 for Mac OS X. Correlation analysis used Pearson's correlation coefficient ( $\mathrm{r}$ ) and the Spearman rank correlation coefficient (rs) for data with Gaussian and non-Gaussian distribution, respectively. Repeated-measures ANOVA was used to compare data sampled from $>2$ populations that follow a Gaussian distribution. Dunnett's multiple comparison test and Tukey's multiple comparison test were used to then identify where statistical significance was present. The Wilcoxon signed rank non-parametric test was used to compare two groups of non-Gaussian data. Normal distribution was tested by using the D'Agostino-Pearson normality test. This computes skewness and kurtosis to quantify how far from Gaussian the distribution is in terms of asymmetry and shape, and how far each value differs from the value expected with a Gaussian distribution. For linear regression analysis, an R2 value was used, where a value of 1.0 shows perfect linearity. Difference plots for method comparison were done by the method of Bland and Altman [15]. For all analyses, statistical significance was considered as $\mathrm{P}<0.05$.

\section{Results}

For the clinical validation, twenty patients ( 8 males and 12 females) referred for parenteral nutrition (PN) were recruited for the study. Baseline characteristics of the subjects are shown in Table 1.

Mean duration of PN administration was 13.9 days (SD 8.5 days, range 5 - 38 days). All patients had a baseline serum IGF-II concentration of $<48.3 \mathrm{nmol} / \mathrm{L}$ (mean $33.0 \mathrm{nmol} / \mathrm{L}$, range $22.2-48.3 \mathrm{nmol} / \mathrm{L}$ ) (measured by RIA). The recruited patients had a mean IGF-II: IGF-I molar ratio of 5.06, with a range of $2.24-9.45$ (reference range $<10$ ). IGF-II and IGF-I were measured by RIA and immunometric assay, respectively. Data for baseline IGF-II (measured by ELISAs) and IGF-II: IGF-I molar ratio were analysed to assess whether the values correlated with BMI, percentage weight loss, 'MUST' score and weight (Table 2).

Significant positive correlation was observed between baseline serum IGF-II measured by the non-extraction ELISA and both BMI and weight. The baseline serum IGF-II measured by the extraction ELISA had significant positive 

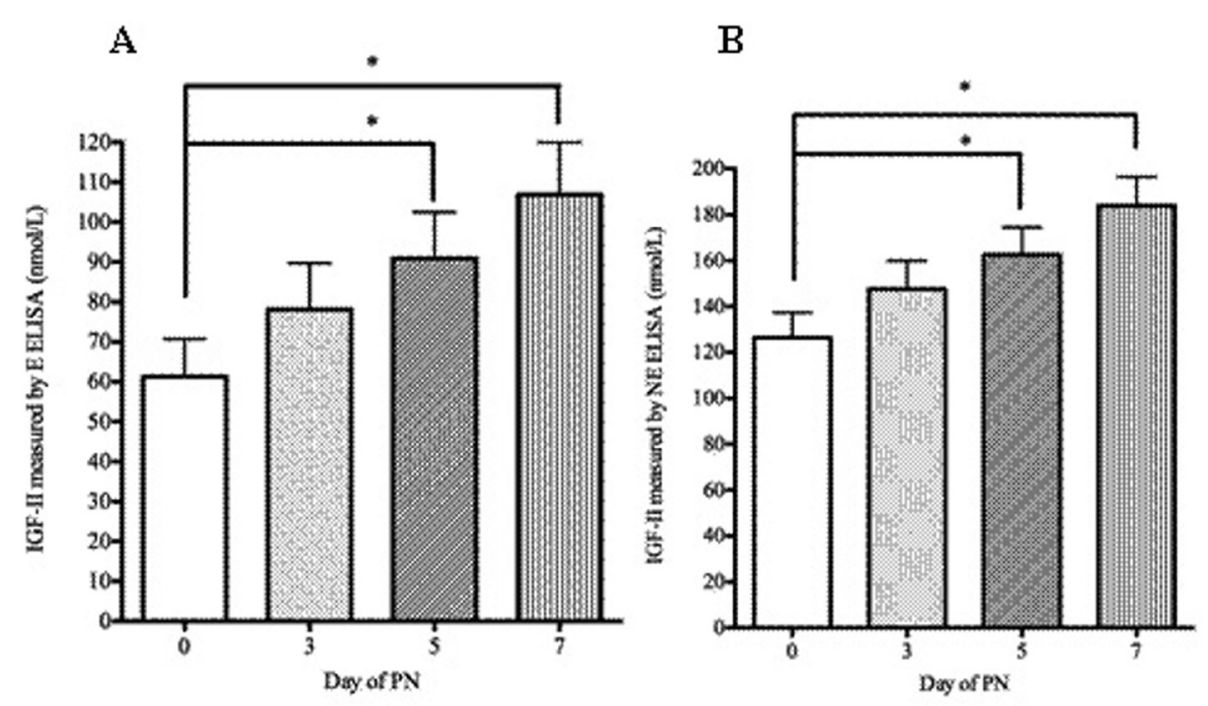

$\mathrm{C}$

$\mathrm{D}$
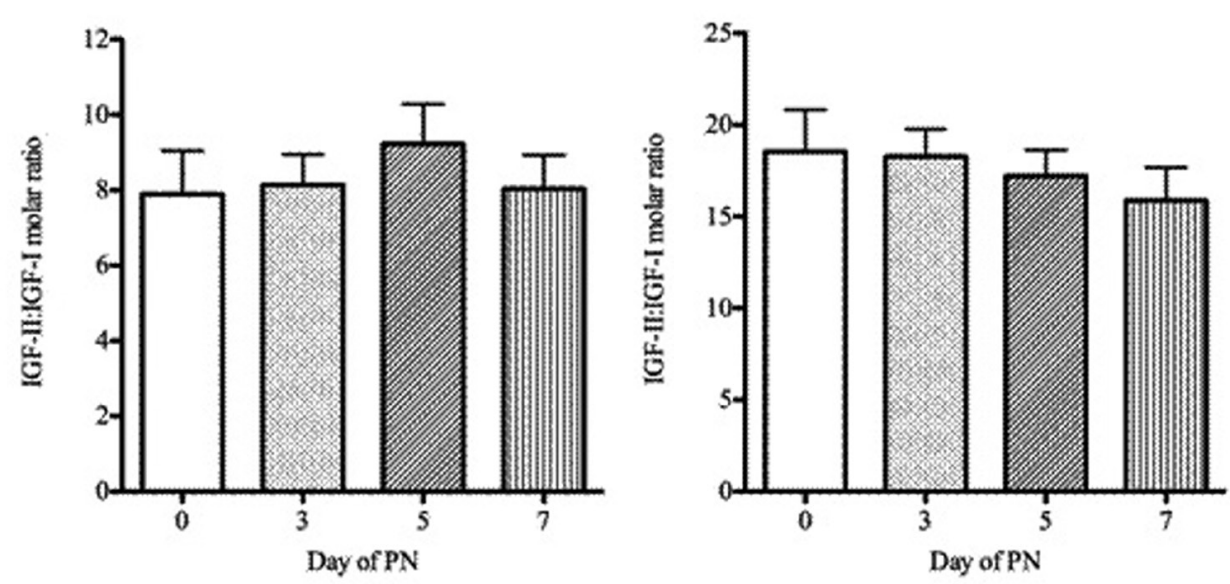

Figure 2. IGF-II concentrations measured by ELISA and IGFII-IGF-I molar ratio in patients receiving parenteral nutrition. Serum IGF-II (A, B), IGF-II: IGF-I molar ratio (C, D) in patients at baseline (day 0) and days three, five and seven of PN administration. $A$ and $C$ were measured by extraction ELISA and $B$ and $D$ by non-extraction ELISA). Serum IGF-II and the IGF-II: IGF-I molar ratio were tested for significance using repeated measures ANOVA with Dunnett's multiple comparison tests. ${ }^{*} \mathrm{P}<0.05$. Error bars are + SEM.

correlation with weight alone. The IGF-II: IGF-I molar ratio, using IGF-II measured by the extraction ELISA had a significant correlation with baseline BMI.

The mean serum IGF-II concentrations and the IGF-II: IGF-I molar ratio of the patients was compared at baseline and days three, five and seven of PN. Figure 1 shows levels measured by RIA and Figure 2 levels measured by ELISA. Comparison of the post-PN IGF-II concentrations to baseline values showed a significant rise at day seven $(\mathrm{P}<0.05)$ (RIA) and at days 5 and $7(\mathrm{P}<0.05)$ (ELISAs). A significant decrease in mean values of the IGF-II: IGF-I ratio at days five and seven $(\mathrm{P}<0.05)$ was observed only where IGF-II had been measured by RIA.

In order to provide information on factors anticipated to confound IGF-II interpretation, the effects of organ dysfunction and the acute phase response (APR) were observed on serum IGF-II concentrations measured by ELISA (Table 3 ).

IGF-II, assayed by the extraction and non-extraction ELISA, showed a strong positive correlation with albumin $(\mathrm{P}<0.0001)$ and a negative correlation with $\mathrm{C}$-reactive protein $(\mathrm{CRP})(\mathrm{P}<0.05)$. The IGF-II: IGF-I molar ratio, using the IGF-II data measured by the extraction ELISA, also had a significant negative correlation with CRP and positive correlation with albumin. The IGF-II: IGF-I molar ratio, using the IGF-II data measured by the non-extraction ELISA, had a significant negative correlation with CRP only. There was a weak positive correlation between creatinine and IGF-II.

In order to assess whether the IGF-II ELISAs could de- 
Table 3. Correlation Analysis of IGF-II and IGF-II:IGF-I Molar Ratio With Biochemical Markers of the APR And Hepatic and Renal Function

\begin{tabular}{|c|c|c|c|c|}
\hline \multirow{2}{*}{ (a) Analyte } & \multicolumn{2}{|c|}{ IGF-II (extraction ELISA) } & \multicolumn{2}{|c|}{ IGF-II:IGF-I molar ratio } \\
\hline & rs & P value & rs & P value \\
\hline CRP & -0.2524 & $0.0248 *$ & -0.3509 & $0.0016^{*}$ \\
\hline Albumin & 0.7032 & $<0.0001^{*}$ & 0.3791 & $0.0007^{*}$ \\
\hline Creatinine & 0.1846 & 0.1034 & 0.1165 & 0.3098 \\
\hline Urea & -0.0498 & 0.6629 & 0.0776 & 0.4993 \\
\hline eGFR & 0.1837 & 0.1051 & 0.1949 & 0.0873 \\
\hline ALP & -0.0834 & 0.4679 & 0.0905 & 0.4337 \\
\hline ALT & 0.1593 & 0.1637 & 0.1323 & 0.2513 \\
\hline $\mathrm{aCa}$ & -0.1124 & 0.3473 & -0.1347 & 0.2627 \\
\hline \multirow{2}{*}{$\begin{array}{l}\text { (b) } \\
\text { Analyte }\end{array}$} & \multicolumn{2}{|c|}{ IGF-II (non-extraction ELISA) } & \multicolumn{2}{|c|}{ IGF-II:IGF-I molar ratio } \\
\hline & rs & P value & rs & P value \\
\hline CRP & -0.3007 & $0.0071 *$ & -0.3194 & $0.0044^{*}$ \\
\hline Albumin & 0.7017 & $<0.0001 *$ & -0.1318 & 0.2533 \\
\hline Creatinine & 0.1632 & 0.1507 & -0.07349 & 0.5226 \\
\hline Urea & -0.0187 & 0.8700 & 0.1718 & 0.1325 \\
\hline eGFR & 0.1837 & 0.1051 & 0.1847 & 0.1054 \\
\hline ALP & -0.1364 & 0.2338 & 0.1308 & 0.2568 \\
\hline ALT & 0.1254 & 0.2740 & -0.0683 & 0.5550 \\
\hline $\mathrm{aCa}$ & -0.05523 & 0.6449 & 0.0508 & 0.6739 \\
\hline
\end{tabular}

Spearman rank correlation and two-tailed P-value were used (a) IGF-II measured using the extraction ELISA; (b) IGF-II measured using the non-extraction ELISA. ${ }^{*} \mathrm{P}<0.05$. Key: aCa, albumin-adjusted calcium; CRP, C-reactive protein; ALP, alkaline phosphatase; ALT, alanine transaminase; eGFR, estimated glomerular filtration rate

tect high IGF-II concentrations, serum was studied from ten patients, all with a confirmed clinical diagnosis of NICTH, in whom IGF-II had previously been measured by RIA. IGF-II was measured by the ELISAs and IGF-I by immunoassay in order to determine the IGF-II: IGF-I molar ratio (Table 4).

Use of the RIA to determine IGF-II, taking an IGF-II: 
Table 4. IGF-II Concentrations and IGF-II:IGF-I Molar Ratio in Patients With Clinical Features Suggestive of $\mathrm{NICTH}$

\begin{tabular}{|c|c|c|c|c|c|c|}
\hline \multirow[b]{2}{*}{ Patient } & \multicolumn{2}{|c|}{ Non-extraction ELISA } & \multicolumn{2}{|c|}{ Extraction ELISA } & \multicolumn{2}{|c|}{ RIA } \\
\hline & $\begin{array}{l}\text { IGF-II } \\
(\mathrm{nmol} / \mathrm{L})\end{array}$ & $\begin{array}{l}\text { IGF-II:IGF-I } \\
\text { molar ratio }\end{array}$ & $\begin{array}{l}\text { IGF-II } \\
(\mathrm{nmol} / \mathrm{L})\end{array}$ & $\begin{array}{l}\text { IGF-II:IGF-I } \\
\text { molar ratio }\end{array}$ & $\begin{array}{l}\text { IGF-II } \\
(\mathrm{nmol} / \mathrm{L})\end{array}$ & $\begin{array}{l}\text { IGF-II:IGF-I } \\
\text { molar ratio }\end{array}$ \\
\hline 1 & 140.0 & 30.4 & 85.3 & 18.6 & 44.2 & 9.6 \\
\hline 2 & 161.4 & 17.9 & 177.7 & 19.7 & 89.0 & 9.9 \\
\hline 3 & 69.5 & 20.4 & 12.4 & 3.7 & 25.4 & 7.3 \\
\hline 4 & 270.9 & 13.8 & 196.9 & 10.0 & 74.8 & 3.8 \\
\hline 5 & 232.8 & ND & 246.7 & ND & 83.4 & ND \\
\hline 6 & 121.5 & 35.7 & 49.2 & 14.5 & 92.8 & 27.3 \\
\hline 7 & 233.4 & ND & 159.4 & ND & 81.0 & ND \\
\hline 8 & 196.1 & 47.8 & 66.7 & 16.3 & 129.2 & 31.5 \\
\hline 9 & 281.1 & 72.1 & 187.7 & 48.1 & 120.7 & 30.9 \\
\hline 10 & 235.4 & 31.0 & 65.8 & 8.7 & 168.5 & 22.2 \\
\hline
\end{tabular}

IGF-II was measured using the extraction and non-extraction IGF-II ELISA's in serum from patients with possible NICTH in whom IGF-II had previously been measured by RIA. Key: ND = not determined due to IGF-I concentration being below the detection limit for the immunoassay $(<3.2 \mathrm{nmol} / \mathrm{L})$. False positive and negative results are shown in bold and bold italics, respectively.

IGF-I molar ratio of $>10$ as diagnostic of NICTH, suggested that four of the patients $(6,8,9$ and 10$)$ had NICTH. Patients 1 and 2 had equivocal ratios and these specimens would have been investigated further by size exclusion chromatography and by measuring IGFBP-2. Further testing may also been done on patients 5 and 7, as the IGF-II: IGF-I molar ratio could not be calculated due to the IGF-I concentration being below the detection limit for the assay. Patients 3 and 4 were negative as the molar ratio was $<10$. Both ELISAs yielded higher IGF-II results than the RIA. In all patients considered to have NICTH, the IGF-II concentration was observed to be higher than the URL of $65 \mathrm{nmol} / \mathrm{L}$ as measured by RIA. As a result, the non-extraction ELISA yielded two false positive results and the extraction ELISA one false positive and one false negative result.

IGF-II results by both ELISA assays were compared to those of the RIA in Bland-Altman difference plots and by regression analysis from a total of 23 healthy volunteers and
79 patient specimens (Fig. 3). Each method correlated well with the RIA and $\mathrm{R}^{2}$ values were similar. Both ELISA methods showed a proportional positive bias, highest at high IGFII concentrations.

\section{Discussion}

This study aimed to clinically validate two ELISAs for IGFII with a view to determining whether either could replace the in-house RIA, currently used for investigation of patients with possible NICTH and to provide information relevant to the utility of IGF-II as a nutritional marker. The patients referred for PN were at high nutritional risk as indicated by their 'MUST' scores. In these patients the baseline serum IGF-II concentration measured by the non-extraction ELISA correlated positively with BMI and weight. IGF-II measured by the extraction ELISA correlated positively with baseline 

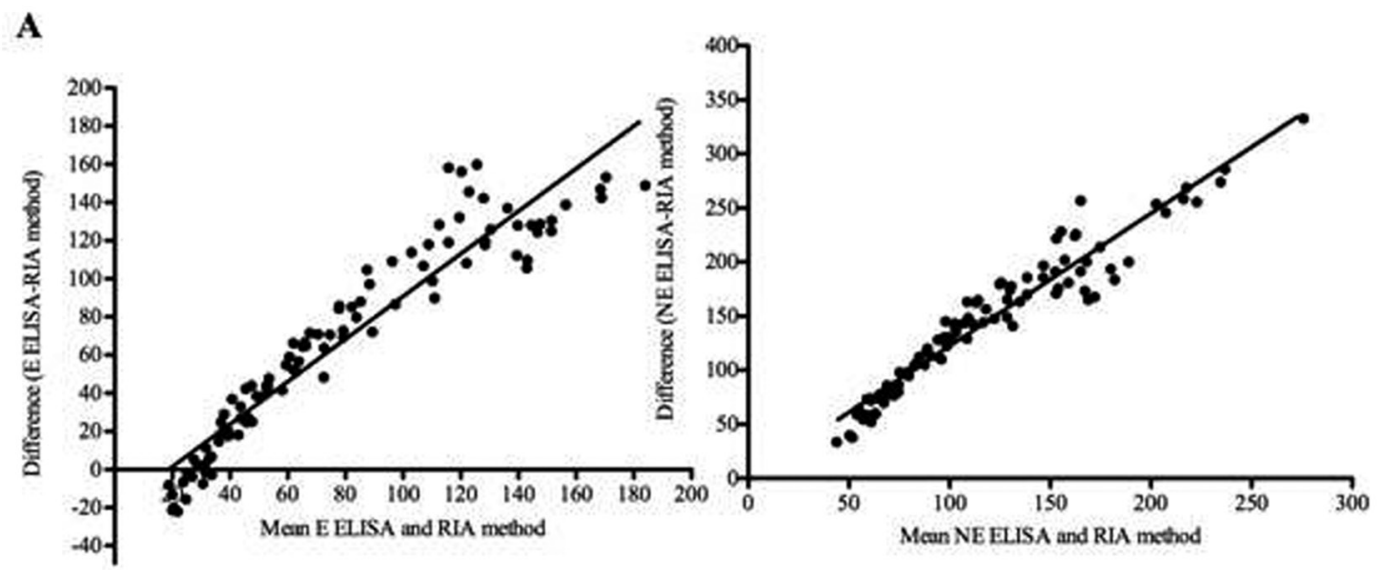

B
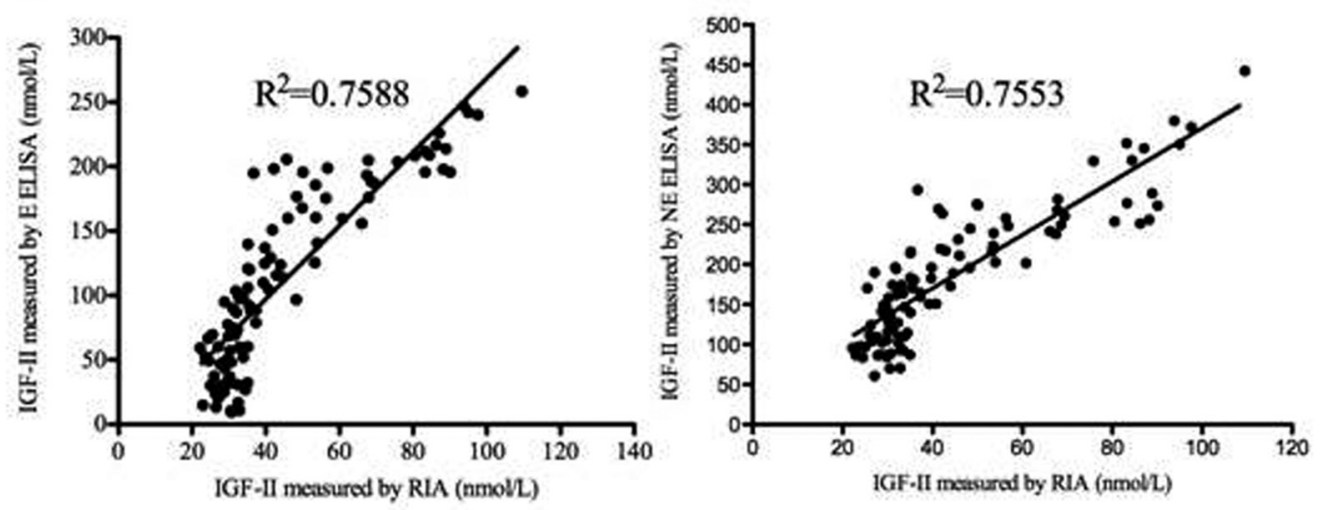

Figure 3. A. Bland Altman plots comparing IGF-II extraction (E) and non-extraction (NE) ELISA assays to RIA. B. Correlation analysis comparing IGF-II extraction and non-extraction ELISAs to the RIA, using the Pearson correlation coefficient, $R^{2}$. Results are shown from IGF-II levels measured on a total of 23 healthy volunteers and 79 patient specimens.

weight alone. This data supports validity of the IGF-II measurements by the ELISA assays. The IGF-II: IGF-I molar ratio at baseline correlated positively with BMI, when using the IGF-II measured by the extraction ELISA, but no correlation with any of the other markers of malnutrition suggesting that this parameter is of limited value in nutritional contexts. No correlation was identified with percentage weight loss within the previous six months or 'MUST' score. This suggests that, in common with IGF-I, IGF-II would be unlikely to perform well in screening for malnutrition in hospital patients.

Baseline serum IGF-II, measured by ELISA and IGF-II: IGF-I molar ratio were compared to serum concentrations during PN administration. Serum IGF-II increased with duration of PN achieving statistical significance at days five and seven. The relatively modest increase in IGF-II concentrations observed may reflect the relatively short follow-up period during which subjects had gained relatively little weight. As is standard practice, nutritional provision was increased gradually and did not generally meet full energy and nitrogen requirements until at least day five. This would likely have influenced the rate of increase in IGF-II concen- trations. These changes are in line with those of Thissen et al [7] who suggested that IGF-II was less sensitive than IGFI to short-term nutrient restriction. Nevertheless the present findings provide further support for the clinical validity of the measurements made by ELISA and suggest that whilst IGF-II is likely to be of little value in nutritional screening, it may have a place in managing nutritional support provision. Unlike serum IGF-II, the IGF-II: IGF-I molar ratio tended to decrease during PN administration, when using the IGF-II concentrations measured by the non-extraction ELISA. This was due to a disproportionate increase in IGF-I concentrations, which is more sensitive to short term changes in nutritional status. This suggests that the ratio may be more useful marker of nutrition during PN administration. However, it has the logistical disadvantage of requiring measurement of both IGFs.

In view of the factors known to confound interpretation of IGF-I viz liver disease and the APR, it was considered appropriate to investigate possible disease influences upon IGF-II concentrations in the study subjects. This was done using correlation analysis between IGF-II and common 
biochemical markers. The APR was assessed by measuring CRP and albumin which are positive and negative acute phase markers respectively. IGF-II correlated strongly with albumin and had a weaker negative correlation with CRP. This suggests that the APR negatively affects serum IGF-II concentrations, a finding in line with studies of IGF-I [16, 17]. Clearly this observation should be taken into account in interpreting IGF-II results.

No correlation was observed between liver enzyme results and serum IGF-II. However, this data should not be taken to imply that IGF-II concentrations are uninfluenced by liver pathology. ALP and ALT are crude markers of liver disease which can remain within normal limits even in extensive liver disease. In addition, most of the study subjects did not have markedly deranged LFTs or significant liver problems. There may not therefore have been a sufficient range of enzyme values in this study for meaningful analysis. Wu et al [18] observed that serum IGF-I and -II concentrations were significantly lower in patients with liver cirrhosis than those in a control group and correlated with the degree of liver dysfunction. They suggested that serum IGF-II concentration could be an important indicator for both hepatic dysfunction and clinical prognosis. Nikolic et al [19] demonstrated that serum IGF-II concentrations reflected compromised hepatic function more closely that those of IGF-I.

Analysis identified a weak positive correlation between IGF-II and creatinine suggesting that IGF-II concentrations climb in renal impairment. This is at odds with the results of other studies, IGF-I and IGF-II concentrationss having been observed to be reduced by up to $60 \%$ in patients with renal failure or nephrotic syndrome [20]. Less data is available on the influence of CKD on serum IGF-II. Daughaday and Trivedi [21] observed patients receiving haemodialysis to have increased serum IGF-II concentrations, though this study measured only the E domain of pro-IGF-II. These studies are not directly comparable with the present work as none of the patients in the present study had renal failure. This matter needs to be investigated further by specifically designed studies.

Of the subjects investigated, $60 \%$ had malignancies. This may have directly influenced IGF-II concentrations, as IGFs are produced by many tumours e.g. most human lung cancers over express IGF-I, IGF-II, and the type 1 IGF receptor (Pavelic et al, 2007) [22]. IGF concentrations tend to be related to tumour size and fall upon tumour debulking. This is an important confounding factor which should be borne in mind in interpreting IGF-II concentrations.

Given that investigation of possible NICTH is currently the only clinical indication for measurement of IGF-II and that use of an ELISA would offer potential logistical advantages over the RIA, a secondary aim of this study was to assess whether the ELISAs could detect elevated serum concentrations of IGF-II observed in patients with NICTH. Both the extraction and non-extraction ELISAs were able to detect
NICTH, but had a positive bias compared to the RIA as demonstrated by Bland-Altman plots. The reason for the positive bias is uncertain but could be due to the assays cross-reacting with other components of the IGF system when IGF-II is present at high concentrations. This would need to be investigated in future studies and, if confirmed, militates against the use of the ELISAs for clinical purposes. Both ELISAs also yielded false positive results (based on the IGF-II: IGF-I molar ratio URL of $<10$ by RIA), and the extraction ELISA one false negative result. Whilst the ELISAs efficiently detected increases in mature IGF-II, there are differences in cross-reactivity with 'big-IGF-II' between the ELISAs and RIA in that the RIA is known to detect 'big-IGF-II' whereas the ELISAs may not. They may therefore yield false negative results where there is a predominantly an increase in 'big-IGF-II' with only a small increase in total IGF-II, as is often the case in NICTH. This militates against use of the ELISAs in this context. Rigorous investigation of this would a much larger number of subjects, but such a study would be difficult given the extreme rarity of NICTH.

In conclusion, two commercially-available IGF-II ELISAs were evaluated with a view to potentially replacing the in-house IGF-II RIA currently used in the SAS Peptide Hormones laboratory. They were able to detect IGF-II concentrations in malnourished patients which correlated with anthropometric measurements and climbed modestly in response to nutrition support. IGF-II is certainly worthy of further study of its utility as a nutritional marker. Whilst the ELISAs are sensitive and can efficiently detect elevated concentrations of mature IGF-II, they are unlikely to replace the RIA for the purpose of investigating NICTH due to their inability to detect 'big-IGF-II'.

\section{Grant Support}

This work was funded by funds available for research and development in the Peptide Hormones SAS.

\section{Conflicts of Interest}

The authors declare no conflicts of interest.

\section{References}

1. Denley A, Cosgrove LJ, Booker GW, Wallace JC, Forbes BE. Molecular interactions of the IGF system. Cytokine Growth Factor Rev. 2005;16(4-5):421-439.

2. O'Dell SD, Day IN. Insulin-like growth factor II (IGFII). Int J Biochem Cell Biol. 1998;30(7):767-771.

3. Yu H, Rohan T. Role of the insulin-like growth factor family in cancer development and progression. J Natl 
Cancer Inst. 2000;92(18):1472-1489.

4. Smith WJ, Underwood LE, Clemmons DR. Effects of caloric or protein restriction on insulin-like growth factor-I (IGF-I) and IGF-binding proteins in children and adults. J Clin Endocrinol Metab. 1995;80(2):443-449.

5. Counts DR, Gwirtsman H, Carlsson LM, Lesem M, Cutler GB, Jr. The effect of anorexia nervosa and refeeding on growth hormone-binding protein, the insulin-like growth factors (IGFs), and the IGF-binding proteins. J Clin Endocrinol Metab. 1992;75(3):762-767.

6. Pucilowska JB, Davenport ML, Kabir I, Clemmons DR, Thissen JP, Butler T, Underwood LE. The effect of dietary protein supplementation on insulin-like growth factors (IGFs) and IGF-binding proteins in children with shigellosis. J Clin Endocrinol Metab. 1993;77(6):15161521.

7. Thissen JP, Ketelslegers JM, Underwood LE. Nutritional regulation of the insulin-like growth factors. Endocr Rev. 1994;15(1):80-101.

8. Frystyk J, Skjaerbaek C, Vestbo E, Fisker S, Orskov H. Circulating levels of free insulin-like growth factors in obese subjects: the impact of type 2 diabetes. Diabetes Metab Res Rev. 1999;15(5):314-322.

9. Teale JD, Marks V. Inappropriately elevated plasma insulin-like growth factor II in relation to suppressed insulin-like growth factor I in the diagnosis of non-islet cell tumour hypoglycaemia. Clin Endocrinol (Oxf). 1990;33(1):87-98.

10. de Groot JW, Rikhof B, van Doorn J, Bilo HJ, Alleman MA, Honkoop AH, van der Graaf WT. Non-islet cell tumour-induced hypoglycaemia: a review of the literature including two new cases. Endocr Relat Cancer. 2007;14(4):979-993.

11. Marks V, Teale JD. Tumours producing hypoglycaemia. Endocrine-Related Cancer. 1998; 5: 111-29.

12. Teale JD, Marks V. Glucocorticoid therapy suppresses abnormal secretion of big IGF-II by non-islet cell tumours inducing hypoglycaemia (NICTH). Clin Endocrinol (Oxf). 1998;49(4):491-498.

13. Christofilis MA, Remacle-Bonnet M, Atlan-Gepner
C, Garrouste F, Vialettes B, Fuentes P, Guidicelli R, et al. Study of serum big-insulin-like growth factor (IGF)-II and IGF binding proteins in two patients with extrapancreatic tumor hypoglycemia, using a combination of Western blotting methods. Eur J Endocrinol. 1998;139(3):317-322.

14. Elia M. The 'MUST' report. Nutritional screening of adults: a multidisciplinary responsibility. BAPEN, 2003.

15. Bland JM, Altman DG. Statistical methods for assessing agreement between two methods of clinical measurement. Lancet. 1986;1(8476):307-310.

16. Raynaud-Simon A, Perin L, Meaume S, Lesourd B, Moulias R, Postel-Vinay MC, Le Bouc Y. IGF-I, IGF-I-binding proteins and $\mathrm{GH}-$ binding protein in malnourished elderly patients with inflammation receiving refeeding therapy. Eur J Endocrinol. 2002;146(5):657-665.

17. Nedelec B, de Oliveira A, Garrel DR. Acute phase modulation of systemic insulin-like growth factor-1 and its binding proteins after major burn injuries. Crit Care Med. 2003;31(6):1794-1801.

18. Wu YL, Ye J, Zhang S, Zhong J, Xi RP. Clinical significance of serum IGF-I, IGF-II and IGFBP-3 in liver cirrhosis. World J Gastroenterol. 2004;10(18):2740-2743.

19. Nikolic JA, Todorovic V, Bozic M, Tosic L, Bulajic M, Alempijevic T, Nedic O, et al. Serum insulin-like growth factor (IGF)-II is more closely associated with liver dysfunction than is IGF-I in patients with cirrhosis. Clin Chim Acta. 2000;294(1-2):169-177.

20. Hirschberg R, Adler S. Insulin-like growth factor system and the kidney: physiology, pathophysiology, and therapeutic implications. Am J Kidney Dis. 1998;31(6):901919.

21. Daughaday WH, Trivedi B. Heterogeneity of serum peptides with immunoactivity detected by a radioimmunoassay for proinsulin-like growth factor-II E domain: description of a free E domain peptide in serum. J Clin Endocrinol Metab. 1992;75(2):641-645.

22. Pavelic J, Matijevic T, Knezevic J. Biological \& physiological aspects of action of insulin-like growth factor peptide family. Indian J Med Res. 2007;125(4):511-522. 